\title{
Key performance indicators of high-tech enterprises
}

\author{
Tatyana Verevka $^{1 *}$ \\ ${ }^{1}$ Peter the Great St. Petersburg Polytechnic University, Institute of Industrial Management, \\ Economics and Trade, Higher Engineering-Economical School, 195251 Polytechnicheskaya st. 29, \\ Russian Federation
}

\begin{abstract}
In the conditions of the transition to innovative development and digital economy, the unconditional priority is shifted to restoration and transformation of high-tech enterprises. The stability of their strategic developing greatly depends on the efficiency of their business activity and the system of the enterprise strategic management. This article defines the basic performance indicators of high-tech enterprises, the particular features of the system to evaluate the efficiency of strategic management of a high-tech enterprise: innovative, scientific-technological and intellectual potential. On the basis of the analysis of the methods widely used all over the world, we developed a system key performance indicators to evaluate the efficiency of high-tech enterprises, with consideration of particular features of operation and development of high-tech enterprises, to enable evaluating the efficiency of their business activities and management through analyzing the inter-related financial and non-financial performance indicators. The practical implementation of this system will make it possible for high-tech enterprises to form a data base for making strategic solutions to ensure competitive advantage of these enterprises and, as a consequence, facilitate their steady development.
\end{abstract}

\section{Introduction}

In the conditions of the transition to innovative development and digital economy, the unconditional priority is shifted to creating and developing new technologies, restoration and transforming high-tech industrial enterprises, as well as ensuring their steady strategic development aimed at manufacturing innovative product. Such enterprises cannot find solutions to these tasks without creating a system of informational-spatial strategic milestones and implementing up-to-date evaluation tools.

The purpose of the research is theoretical-methodological substantiation and development of practical recommendations for forming a system of key performance indicators to evaluate the efficiency of management of high-tech enterprises in four most important strategic perspectives (customers, finance, internal processes and workforce) on the basis of the approaches used worldwide.

\footnotetext{
${ }^{*}$ Corresponding author: verevkatv@mail.ru
} 
Due to direct state support - federal target programs, the state program for the development of the defense industry complex.

With the general theoretical comprehension of the usefulness of a modern system of performance indicators to evaluate the efficiency of the enterprise management, the content and the selection criteria of performance indicators, as well as the calculation methods proposed by authors of research works are quite various, which emphasizes the importance of this topic and highlights the perspectives and the direction of further scientific research.

One of the most widely used methods to evaluate the efficiency of strategic management of financial and business activity are as follows:

- performance indicators $E V A$ to evaluate the increase in the price of the capital;

- a system of balanced performance indicators $(B S C)$ [1];

- key performance indicators of efficiency developed by David Parmenter(KPI) [2];

- multi-factormodelsDuPont [3] and some others.

The basis of all these methodsis the system of strategic performance indicators forming an informational-spatial base in accordance withthe specified purpose of the enterprise.

An outstanding place among thesemethods is occupied by a balanced system of performance indicators developed by American scholars R.Kaplan and D.Norton (BSC, Balanced Scorecard) [1]. This concept is made of four components: "Finance", "Customers", "Business processes" and "Workforce"that are inter-related through the cause-and-effect relations. While solving the problems of evaluating the efficiency of their activity, enterprises focus on the $B S C$ approach more and more actively.However, the main deficiency of the $B S C$ approach is lack of concise performance indicators (with their calculation methods) to evaluate the strategic objectives, which greatly hampers their applicability to enterprises of various industries and, especially, in the high-tech sphere.

In most information sources high technologies are defined differently, as scienceintensive, progressive, new, innovative, break-through, new-wave technologies etc.

In thedocuments adopted by the European community, high technologies are defined as a "system of knowledge, industrial and otheroperations, methods and processescorresponding or surpassing world analogues in their quality performance indicators..." [4].

According tothe rules of international and Russian statistics, grouping the products, enterprises and industries by their technological level (high-, medium- and low-technology) is carried out on the basis of the performance indicator ofscience intensity.

High-technologyindustries (products) are those whose level of science intensitycalculated as a ratio between the total cost of $R \& D$ and the revenueis above the average level for the investigated combination. For example, RosStat (Russian Statistics administration)considers pharmaceutics, electronics, telecommunication, aviation and space industries as high-tech level, whereas chemical industry, engineering, motor car industry, shipbuilding and other transport industry are considered as high-level medium-technology level.

It should be noted that science intensity of Russian enterprises is much lower than that of their foreign competitors in the corresponding industries. Obviously, the low level of interest from enterprises towards technological innovations during many years, insufficient investments into the innovative sphere from the business and the state, has led to sufficient technological weakness of the Russian industry. In order to correct that, the state took extraordinary measures to stimulate perspective directions of development of modern technologies (transport, space systems, nano-technologies, nuclear industry etc.). As a result, the enterprises carrying out research and development in these spheres have significant taxation advantages causingthe decrease in the taxation base for revenue oneand-a-half as to the actual costs of R\&D. 
The objective of the state strategy of innovativedeveloping in the RF is reaching the performance indicator for science intensityfor the largest Russian enterprises to the level of similar foreign enterprises in the respective industries.

However, large investment into the R\&D does not guarantee the result. For example, in motor car manufacturing, the industry-average level of science intensity is $4-5 \%$ (Volkswagen- 5.3\%, Toyota Motor Corporation- 3.8\%, General MotorsCompany- 4.9\%, Ford MotorsCompany- 4.8\%, Daimler AG- 4.2\%, Honda Motor Co., Ltd- 4.9\%). The performance indicator for science intensity of Porsche is twice as high as the industryaverage, whereas this value forHyundai Motoris five times as low [5]. Nevertheless, during the last decade, the price of the brandHyundai has grown three times (from 4.1 to 12.5 billion dollars), and, as a result, Hyundaihas become the sixth largest motor car brand, overtaking Volkswagen (11.4 billion dollars) and Porsche (9.5 billion dollars), and the 35thworld-largest brand in all the industries [6].

Another very spectacular illustration is not only the most expensive brand but also the most efficient innovator in the world - Apple Inc.that, even though spending less than 5\% of revenue for R\&D (3.5\% in 2016and 4.7\% in 2017), i.e.almost three times less than their competitor Cisco Systems, Inc. (12.6\% in 2016and 12.8\% in 2017), shows one of the highest growth in the revenue and market capitalization, and,during seven years, is number one on the list "The 10 Most Innovative Enterprises", as selected by the world experts in the sphere of innovations.Moreover, as noted by the experts of the consulting-auditing company $P w C$, during the entire period of this list rating, starting from 2010, the ten most innovative enterprises are ahead of the ten enterprises leading in the level of expenditures for R\&D from the viewpoint of key performance indicators of efficiency of their business and financial activity [7].

Therefore, the stability of the strategic innovativedevelopment of high-tech enterprises is greatly affected by the efficiency of their business and financial activity and the efficiency of their managementsystem.

Definitely, as we develop the strategic map and the efficiency evaluation performance indicators, we should consider the particular features of the operating system of high-tech enterprises, whose common attributes are the following:

- science intensity and high significance of R\&D results during the entire manufacturing cycle, which makes it possible to attribute $R \& D$ to the basic internal operating processes of high-tech enterprises;

- highly qualified (intellectual)workforce potential;

- a significant share of non-material assets (intellectual property) in the stock;

- a powerful industrial and technological platform that makes it possible to develop and implement innovations (scientific-technological or other potential of commercialization);

- a large added valuein the final product;

- high risks and input of the innovative process.

These particular features will cause certain difficulties while developing a systemof key performance indicators for efficiency evaluation for high-tech enterprises.

As a universal set of performance indicators for efficiency evaluation of a high-tech enterprise, the following can be included.

\section{Financial activity evaluation of the enterprise}

The financial evaluation of the efficiency of a high-techenterprise, with consideration of a high added value in the final product, can be carried out on the basis of dynamics of the economic added value (EVA,Economic Value Added) calculatedby the formula (1): 


$$
E V A=N O P A T-C E \times W A C C,
$$

whereNOPAT is the net operating profit after taxes, without the interest; $W A C C$ is the weighted average cost of capital;CEis the capital employed.

The positive dynamics of this performance indicator means that the enterpriseoperates efficiently and its market value is increasing.

An advantage of this method in comparison toDuPont models is focusing not as much on the profitability of capital but on the increase in the price of the enterprise, which is especially important for diagnosing efficiency in the innovative sector. A drawback of this method, similarly to DuPont models, is focusing on the financial targets of the enterprise, which does not allow accurate evaluation of all the components of the system [8].

\section{Evaluation of customer satisfaction}

An integrated indicator reflecting the quality of the services provided is the index of actual and potential customers' satisfaction(CSI, Customer Satisfaction Index) calculated by the formula from the points received with a questionnaire for customers (2):

$$
C S I=\sum_{n=1}^{N} F_{n} \cdot W_{n},
$$

where CSIis the customer satisfaction index; $F_{n}$ is the evaluation of the index number $n ; N$ is the total number of indexes; $W_{n}$ is the relevance (weight) of the index number $n$ $\left(\sum_{n=1}^{N} W_{n}=1\right)$.

Evaluation of the competitive advantage of the enterprise is usually done by calculating the index of competitive advantage. However, when calculating this index for high-tech enterprises, their product should be compared with world analogues. This process includes the following: analysis of similar industries and similar products; finding additional features and performance indicators for the products that ensure their competitive advantage; finding the basic performance indicators to be used forevaluation; evaluation of perspective products from competitors.

At the same time, besides using the general strategic performance indicators, the system of performance indicators for evaluation of high-tech enterpriseshas its own particular featuresconditioned by the specific character of this sphere, whose attributes have been investigated above. The primary particular performance indicators of the system is the innovativepotential, which the author considers as a complex of all the resources required to solve the innovative tasks and defining the readiness of the enterprisefor solving them. In the author's opinion, two main components of the innovativepotential are the intellectualpotential and the scientific-technological potential (potential of commercialization).

Let us comprehend how these aspects can be taken into consideration when developing a system of strategic performance indicators of the activity of high-tech enterprises.

\section{Evaluation of the innovative potential}

Innovation is the main factor influencing the increase of the value of a high-tech enterprise. Therefore, the efficiency of innovations greatly contributes to the success of such enterprises.

Within the framework ofthe strategic managementsystem of the enterpriseit is important that innovative projects be carried out in the specified volume and in due time. Therefore, 
to control the innovative activity, both the preliminary evaluation and continuous monitoring are necessary for the process of innovative projects of the enterprise [9].

Efficiency of using the innovative potential of the enterprisecan be evaluated as the ratio between the cost and the result. The index of using the innovative potential can be expressed as the following formula (3):

$$
R_{I C}=\frac{1}{A} \cdot \sum_{t=1}^{T} \frac{E V A_{t}}{(1+r)^{t}},
$$

where $R_{I C}$ is the index of using the innovative potential; $A$ is thebook value of the enterprise assets; $E V A_{\mathrm{t}}$ is the economic added valueof innovative projects during the year number $t ; r$ isthe rate of discounting.

\section{$5 \quad$ Evaluation of the scientific-technological potential (potential of commercialization)}

New inventions should not only be developed at the enterprise but be implemented in the practical use. As a rule, not all the inventions at high-tech enterprises have practical implementation (commercialization). Therefore, the efficiency of thescientifictechnologicalpotential (potential of commercialization) of the enterprisecan be evaluated asthe ratio between the implemented inventions and the inventions that have been developed or purchased. An index of using the scientific-technological potential $\left(R_{\text {com }}\right)$ is calculated by the following formula (4):

$$
R_{c o m}=\frac{q_{i}}{q_{d}}
$$

where $R_{c o m}$ is the index of using the scientific-technologicalpotential (potential of commercialization); $q_{i}$ is the number of implemented inventions (technical solutionsetc.); $q_{d}$ is the number of developed inventions.

\section{Evaluationof the intellectual potential}

The index of using the intellectual potential $\left(I_{I P}\right)$ can be calculatedby the following formula (5):

$$
I_{I P}=I P(h r) \cdot R_{c o m},
$$

where $I_{I P}$ is the index of using the intellectualpotential; $I P(\mathrm{hr})$ is the intellectual potential of the workforce; $R_{\text {com }}$ is the index of using the scientific-technological potential (potential of commercialization). (6):

The intellectual potential of the workforce can be calculatedby the following formula

$$
I P(h r)=\sum_{j=1}^{j} \frac{I P(h r)_{j}}{J},
$$

where $I P(h r)$ is the intellectual potential of the workforce; $I P(h r)_{j}$ is the intellectual potential of the worker number $j ;$ is the total number of workers. 
The intellectual potential of each worker can be calculatedby the following formula (7):

$$
I P(h r)_{j}=\sum_{n=1}^{N} P j_{n} \times W_{n},
$$

where $I P(h r)_{j}$ is the intellectualpotential of the worker numberj; $P j_{n}$ isevaluation of the parameter numbernof the worker number $j ; N$ is the total number ofparameters; $W_{n}$ is the importance (weight) of the parameter number $n\left(\sum_{n=1}^{N} W_{n}=1\right)$.

The author of this research did not set the task of developing a complete list of performance indicators for the efficiency of high-tech enterprises described in the modern literature on economybut only limited oneself to only some most important key performance indicators for evaluation of strategic managementefficiency ofa high-tech enterprise as shown in Fig. 1.

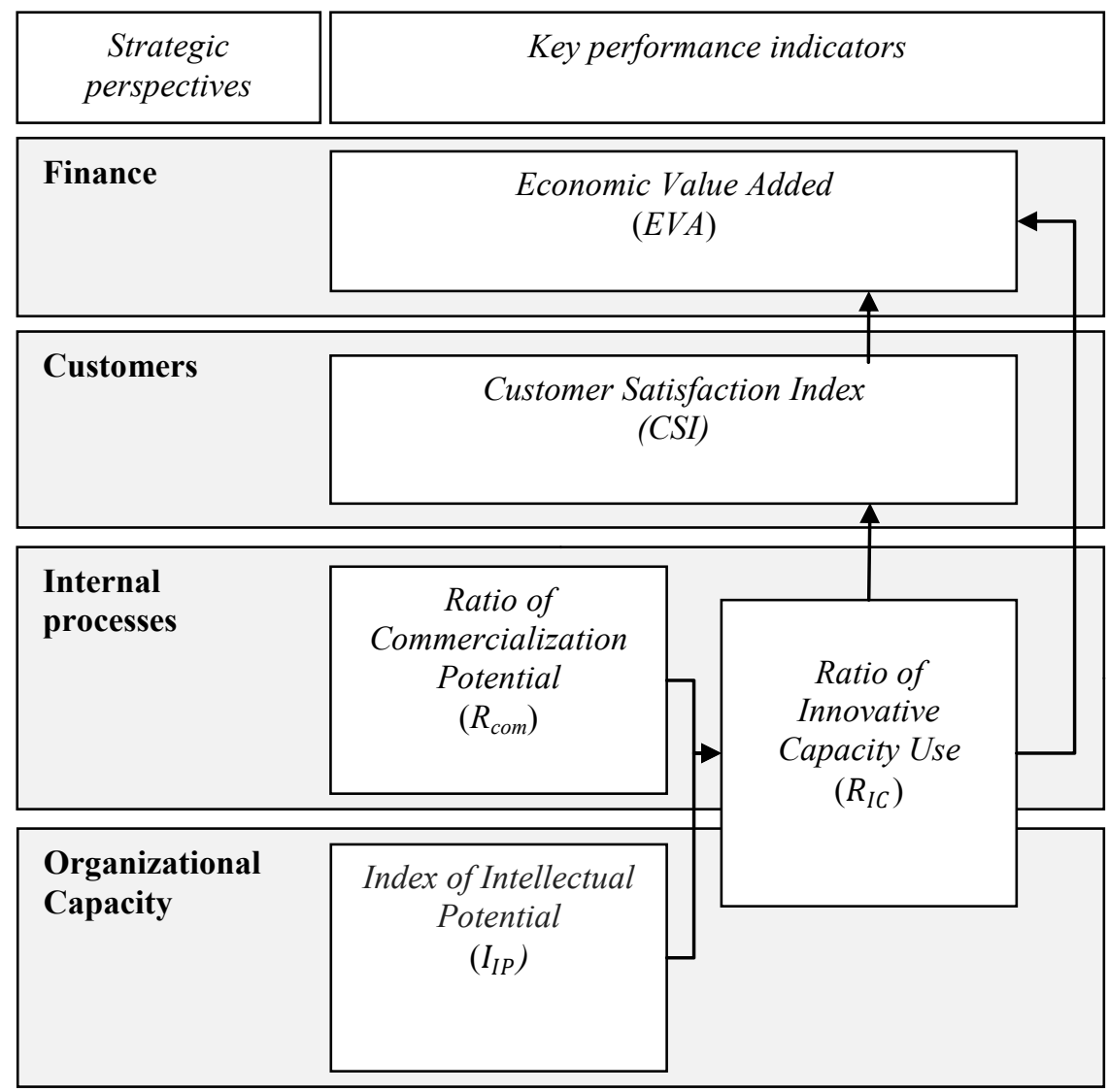

Fig. 1. Strategic perspectives and key performance indicators of a high-tech enterprise.

The scientific novelty of this research consists in the following provisions:

- we defined the basic attributes of a high-tech enterprise and particular features of a system for strategic evaluation of high-tech enterprises conditioned by the specific features of their operating system and the main factors ensuring their competitive advantages: innovative, scientific-technological and intellectual potential of the 
enterprise;

- we offered relevant performance indicators for evaluation of the innovative, scientifictechnological and intellectual potential of a high-tech enterprise, with formulas to calculate them;

- we developed a general system of key performance indicators to evaluate the efficiency of a high-tech enterprise in four most important strategic perspectives:

1) customers - evaluation of customer satisfaction (CSI);

2) finance - evaluation of the financial efficiency of the enterprise (EVA);

3) internal processes - evaluation of the efficiency of using the innovative $\left(R_{I C}\right)$ and scientific-technological $\left(R_{\text {com }}\right)$ potential;

4) workforce - evaluation of using the intellectual potential $\left(I_{I P}\right)$.

2 .

\section{$7 \quad$ Conclusions}

The proposed system of strategic performance indicators takes into consideration the particular features of operating and developing high-tech enterprises and makes it possible to evaluate the efficiency of their financial and business activity and the efficiency of thesystem of strategic management on the basis of inter-related financial and non- financial performance indicators.

The results of the research are presented in the form of concise recommendations and proposals for forming a system of key performance indicators to evaluate the efficiency of high-tech enterprises and can be used when developing a strategic map of a high-tech enterprise. Using this system of performance indicators in combination with definitions of their normative and target values will enable an objective analysis of the state and longterm development of the enterprisewith consideration of its strategic purpose.

\section{References}

1. R. Kaplan, D. Norton, Balanced indicators system. From strategy to action (Olympbusiness, Moscow, 2006)

2. D. Parmenter, Key Performance Indicators. Development, implementation and application of decisive indicators(Olymp-business, Moscow, 2009)

3. M. Phillips, The DuPont invention that changed how things work in the corporate world [online], Available at:https://qz.com/569738/the-dupont-invention-that-foreverchanged-how-things-work-in-the-corporate-world/ (2015)

4. Decision of the Interstate Council of the Eurasian Economic Community on December 11, 2009, No. 475 "On the Concept of the Establishment of the Eurasian Innovation System". The document was not published. Access from the legal system "ConsultantPlus" [online], Available at: http://www.consultant.ru/law/ref/ju_dict/word/vysokie tehnologii/ (2018)

5. Strategy \& 2017 Global Innovation 1000. Annual Strategy \&pwc [online], Available at: https://www.pwc.fr/fr/assets/files/pdf/2017/10/2017-global-innovation-1000.pdf (2018)

6. Best Global Brands - 2017 (Interbrand) / Ranking The Brands [online], Available at:http://interbrand.com/best-brands/best-global-brands/2016/ranking/ (2018)

7. The 10 Most Innovative Companies. [online], Available at: https://www.pwc.ru/en/press-releases/2016/global-innovation-1000.html (2018) 
8. T. V. Verevka, Russia in the global world, 9 (32) (2016)

9. S.V. Koledinov, T.V. Verevka, Science Week SPbPU: materials of a scientific conference with international participation, 38 (2017) 